JOM, Vol. 66, No. 10, 2014

DOI: $10.1007 / \mathrm{s} 11837-014-1143-4$

(C) 2014 The Minerals, Metals \& Materials Society

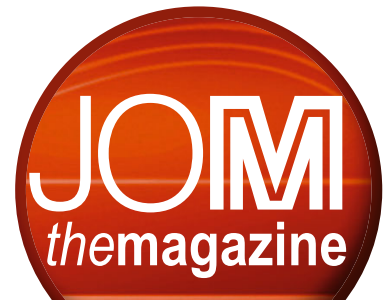

\title{
new and noteworthy at TMS
}

\section{TMS Journals Score Impact Factor Increases}

All four of TMS's long-established journals marked increases in their 2013 Impact Factors (IF), released by the Thomson Reuters ISI Web of Knowledge citation measurement index in July.

"I am delighted to see the continued upward trend in Impact Factors of our flagship publications," said James. J. Robinson, TMS Executive Director. "Each year brings its own set of circumstances that can cause these numbers to go up or down. Whatever the outcome, our editorial teams use this information to continue improving the quality of our journal content. The fact that all of our journals have generally enhanced their IF over time (Figure 1) is testament to the untold hours of hard work that have been logged by our editors and volunteers."

Maureen Byko, TMS Editorial, Content, and Communications Senior Manager, sees a correlation between the steady rise in IF and the significant increase in the quantity of material published in TMS journals over the

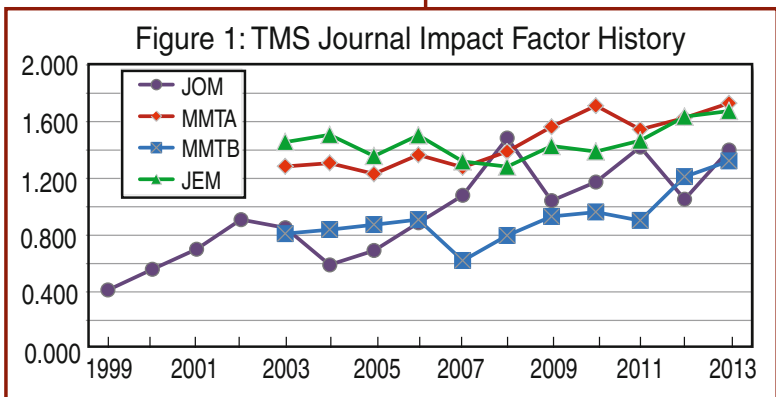

Figure 2: Growth in Number of Published Papers

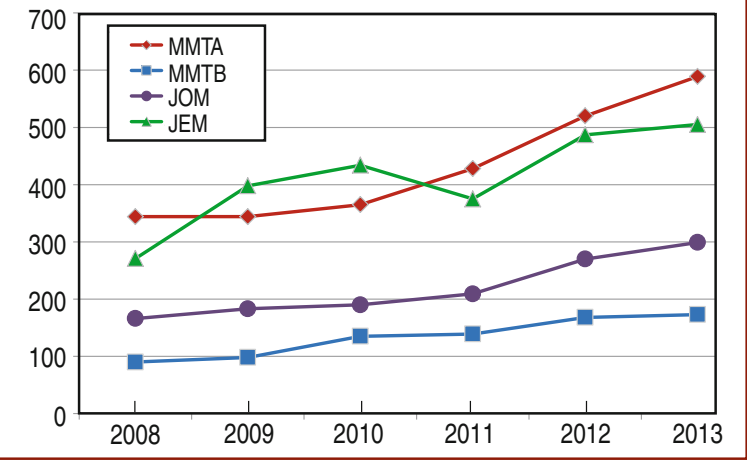
papers make it into our journals," she

(Figure 2). "It's a direct consequence of the diligence of our editors and volunteer advisors to ensure that only high-quality said. "The reputation of our journals is such that they have become a destination for those authors who want to share their best work at the highest level in their profession. The IF is one measure of that reputation, and it's a great validation for those many individuals who have made it possible for our journals to achieve such a high standard."

The IF represents the average number of citations to articles that were published during the preceding two years. It is based on the number of citations of a journal's materials divided by the number of citable materials published by the same journal. Authors often refer to the IF and the subject rankings that they generate (Table I) as a guideline when seeking to maximize exposure of their work.

The target IF ranking for TMS publications is at least " 1 ." This year's IF numbers exceeded those expectations (2012 IF in parentheses):

- Journal of Electronic Materials (JEM): $1.675(1.635)$

- JOM: 1.401 (1.053)

- Metallurgical and Materials Transactions A (MMTA): 1.73 (1.627)

- Metallurgical and Materials Transactions B (MMTB): 1.3 (1.212)

To access TMS's entire library of journals and publications in one convenient location, visit the TMS Knowledge Resource Center at knowledge.tms.org.

\begin{tabular}{|c|c|c|c|c|c|}
\hline I Subject Categories & $\begin{array}{l}\text { Total Journals } \\
\text { in Category }\end{array}$ & JOM & MMTA & MMTB & JEM \\
\hline aterials science, multidisciplinary & 251 & 123 & 90 & 133 & 99 \\
\hline etallurgy \& metallurgical engineering & 75 & 16 & 10 & 19 & \\
\hline ineralogy & 27 & 15 & & & \\
\hline ining \& mineral processing & 21 & 6 & & & \\
\hline ngineering, electrical \& electronic & 247 & & & & 83 \\
\hline hysics, applied & 136 & & & & 55 \\
\hline
\end{tabular}

The ISI Web of Knowledge uses Impact Factors to rank journals within specific subject categories. This table presents all the subject categories assigned to TMS journals, as well as the rank of TMS journals within these categories 


\section{TMS Joins NIST in Celebrating a Century of Discovery in Metallurgy and Polymers}

\section{Robert D. Shull and Chad R. Snyder}

Approximately 200 people converged at the U.S. National Institute of Standards and Technology (NIST), in Gaithersburg, Maryland, on May 20 to celebrate 100 years of metallurgy and 50 years of polymers with the NIST Materials Science and Engineering Division (MSED). TMS was one of the sponsoring organizations of the centennial event.

The program was opened by Willie May, NIST Acting Director, with his talk on the creation of NIST's originally named entity, the National Bureau of Standards (NBS) in 1901 and the Metallurgy Division 12 years later. Eric Lin, Chief, NIST Materials Science and Engineering Division, which contains the previous Metallurgy and Polymers Divisions, also announced the creation of a Centennial Collection in the NIST Digital Library and set the tone for the subsequent six talks, organized by Robert Shull and Chad Snyder. These presentations reviewed a number of highlights at NBS/NIST in metallurgy and polymers over the past century.

Isaac Sanchez, University of TexasAustin, first described some of the major changes in the Polymers Division during the 1970s and 80s, in both its science and organization. NBS, at the time, was heavily involved in trying to resolve several major controversies at the basis of polymer science. One of the strongest was the nature of chain folding in polymer crystallization. While it had been proven by the early 1960s that polymer chain folding must occur during the crystallization process, the nature of the folding process was highly contested. NBS was strongly on the side of "regular" chain folding. The opposing camp was invested in a "random switchboard model" of chain folding. In the end, most researchers in the field accepted the NBS view, but the challenges of developing theories of polymer crystallization remained difficult and controversial for a long time afterwards.

Richard Fields, NIST (retired), followed with descriptions of a series of investigations that the government had requested NBS and NIST to conduct on catastrophic materials failures. For instance, NBS was called in 1913 to determine the cause of the thousands of railroad accidents occurring each year in the early 1900s due to broken rails, wheels, and axles, as well as to suggest solutions. Most of these failures were due to the use of improper materials, in which the ductility and toughness of a material was not taken into account. Similarly, NBS scientists determined, through Charpy

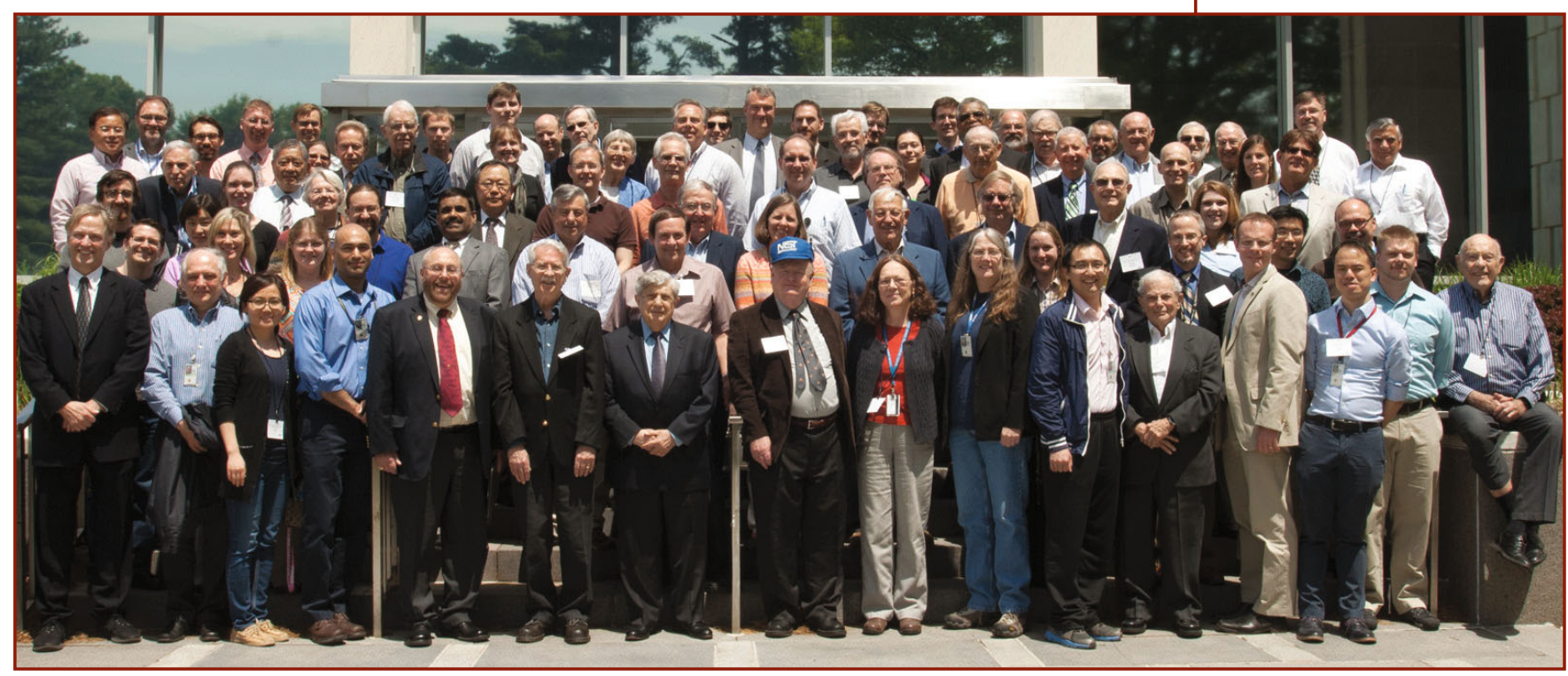

More than 200 attendees celebrated 100 years of metallurgy and polymers at NIST, including five past chiefs of the Metallurgy and Polymers Divisions. 


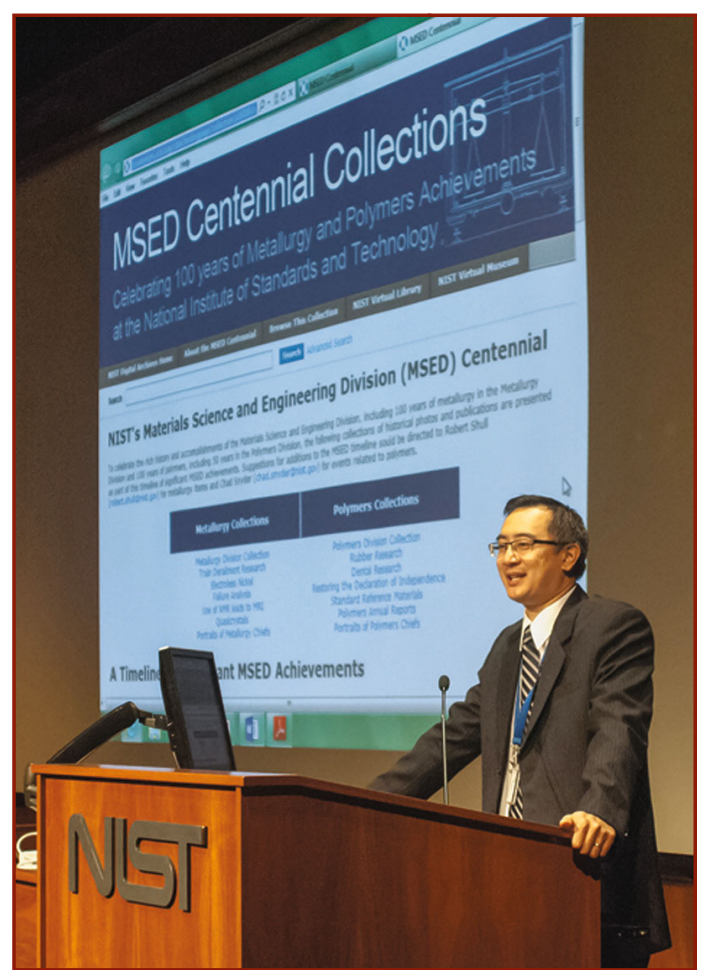

Eric Lin, NIST Materials Science and Engineering Division Chief, announces the creation of a Centennial Collection in the NIST Digital Library. impact tests, that World War II "Liberty" ships were cracking in half when they sailed into the cold north Atlantic waters on the way to England because of a change in ductility of the welded steel at low temperatures. As there were two to three of these ships being launched every day during that time, this was an important discovery. Finally, when the World Trade Center buildings collapsed after the terrorist attack on September 11, 2001, NIST was called in to investigate and subsequently issued the definitive study on the materials relationship to the collapse.

Frank Gayle, NIST, one of the leaders of that World Trade Center study, then described the rich history of NBS/NIST in the discovery of novel crystal structures and both the use and modeling of phase equilibria in materials. One notable example of this was developing the theory of precipitation hardening at NBS in 1919. This enabled aircraft to be made of metal rather than wood. Quasicrystals were also discovered at NBS in 1982 by future Chemistry Nobel Laureate Dan Shechtman, and a whole new industry was spawned by the 1944 NBS discovery of electroless nickel-Electroplaters quickly took it over for use in the automotive, electronics, and aerospace industries. NBS scientists likewise developed the phase field method for modeling microstructure formation during phase transformations, and also spearheaded the worldwide reevaluation of binary alloy phase diagrams with the American Society of Metals International in 1980.

Gregory McKenna, Texas Tech University, next described the early polymers activities that began in the "Rubber Section" around 1911. That activity was timely, since the demand for rubber rose sharply in the 1920 s when the affordable automobile was introduced.
Subsequent British control of natural rubber resources in the Far East caused rubber prices to skyrocket. As the U.S. government was spending around $\$ 1$ million per year on tires at the time, NBS was prompted to extend its product testing to more basic research on natural, reclaimed, and synthetic rubbers, resulting in an NBS invention of a sheet rubber from the guayule bush that compared favorably with the latex from plantation rubber. NBS work on "high polymers" (e.g., chainlike molecules of very high molecular weight) began in 1944. McKenna also discussed the significance of early NBS activities in elucidating the properties of amorphous polymers, including a definitive substantiation of the Frenkel-Flory-Rehner hypothesis of additive elastic deformation energy and free energy of mixing. In particular, NBS demonstrated that the free energy of swollen polymers was the same as that for unswollen polymers (e.g., unaltered by the presence of a solvent), as originally proposed by a later Chemistry Nobel Laureate, Paul J. Flory.

Robert Shull, NIST, then related a series of milestones made in the Metallurgy Division over the past 40 years on elucidating the electronic and magnetic behavior of materials. These included making the first in vivo measurement of the nuclear magnetic resonance of a cancerous tumor, spurring the subsequent development of magnetic resonance imaging (MRI) techniques. NBS scientists also prepared the first thin films of high temperature superconductors by laser-ablation, now the method of choice around the world. The Object Oriented MicroMagnetic Framework (OOMMF) code that is used by more than 50 percent of the world for performing micromagnetic computations was likewise developed in this NBS/NIST Division. And, it was the Metallurgy Division that, for eight years, led the world in making layered thin-film structures having the largest magnetoresistance values at room temperature for the smallest switching fields. Such structures now constitute the read heads in virtually all computer hard disk drives. Magnetic refrigerators may also become a thing of the future due to the NBS prediction and measurement of enhanced magnetocaloric effects in magnetic nanocomposites.

Freddy Khoury, NIST (retired). rounded 
out the symposium speakers. He described the series of milestones performed in the Polymers Division linked to the structure and crystallization of polymers, including revelation of fiber structure through x-ray diffraction, documenting crystallization temperature effects on polymer melting points, and elucidating the relationship between chain folding and lamellar structures. In addition, NBS developed much of the thermodynamics of polymers and theory behind the above topics.

The day concluded with tours of the current Materials Science and Engineering Division laboratories, a presentation highlighting past NBS/NIST colleagues active in polymers and metals research, and networking and conversation over a barbecue dinner on what materials advancements NIST may be leading over the next 100 years.

Robert D. Shull is a NIST Fellow, 2007 TMS President, and 2013 TMS Fellow. Chad R. Snyder is a Research Chemist in the NIST Functional Polymers Group.

\section{Workshop Identifies Priorities for Integrating MGI-Related Research Activities}

The MGI Accelerator Network unites a team of leading materials researchers at the Georgia Institute of Technology (Georgia Tech), the University of Michigan, and the University of Wisconsin-Madison to develop strategy for sharing resources, knowledge, and expertise in developing new materials quickly and efficiently. The network was established to advance the goals and principles of the Materials Genome Initiative (MGI), launched in 2011 under the U.S. Advanced Manufacturing Partnership. "A central goal is to integrate and accelerate MGI research activities going on across the United States," said David McDowell, Georgia Tech Regents Professor and Carter N. Paden Jr. Distinguished Chair in Metals Processing.

In an effort to improve understanding of MGI challenges and to help focus MGIrelated research, the MGI Accelerator Network hosted a workshop on June 5 and 6 at Georgia Tech that drew more than 150 stakeholders from academia, government, and industry. TMS was one of the workshop sponsors and George Spanos, TMS Technical Director, presented a poster on TMS's activities in advancing integrated computational materials engineering (ICME) and manufacturing innovation. A focus of his presentation was the 2013 TMS study, Implementing ICME in the Aerospace, Automotive, and Maritime Industries.

One of the outcomes of the workshop was a series of priorities that include developing an inventory of MGI-related research and infrastructure. "We want to get the most value out of what research is being planned and conducted," says John Allison, Professor, Materials Science and Engineering, University of Michigan, 2002 TMS President, and 2014 TMS Fellow. "A comprehensive picture of these efforts, as well as the physical and cyber infrastructure that exists around the country, will allow materials researchers to form collaborations, identify fundamental engineering problems, share best practices and novel approaches, and to support interdisciplinary communication among industry, academia, and government laboratories, and across geographical boundaries."

\section{DMS Congress Announces Poster Contest Winners}

Congratulations to the following individuals for being selected as the winners of the poster competition "We want to get the most value out of what research is being planned and conducted."

- John Allison, 2002 TMS

President and 2014 TMS Fellow

held during the International Congress on 3D Materials Science 2014 (3DMS), that took place June 29-July 2:

\section{Professional Category:}

"Site Specific 3D Pathway Analysis of Functional Energy Materials" Peter Jørgensen, Tobias Stegk, and Karin Hansen, all from the Technical University of Denmark.

\section{Student Category:}

"A New Design for In-situ Tomographic Tensile Stage" Nicolas Gueninchault, MINES ParisTech; Arthur Desprès, INSA Lyon; Yannick Pannier, École Nationale Supérieure de Mécanique et d'Aérotechnique; Nicolas Lenoir, École des Ponts ParisTech; Henry Proudhon, MINES ParisTech. 


\section{TMS Welcomes New Members}

\section{Please join us in congratulating the following new TMS members, approved by the TMS Board of Directors at its August meeting:}
Aderhold, Patrick J.; United States
Agbenyegah, Gordon E. K.; Volta Aluminium Company, Ghana
Andersen, Olaf; Fraunhofer Society, Germany
Ang, Andrew SM; Swinburne University of Technology, Australia
Babout, Laurent; Lodz University of Technology, Poland
Blanc, Remi; FEl France, France
Bowers, Darren, W.; United States
Brusselle, Nadege; IFP Energies Nouvelles, France
Burnett, Tim; University of Manchester, Great Britain
Caty, Olivier; France
Cavalie, Pierrick; Saint-Gobain Recherche, France
Cisse, Oumar; Amin Electrical \& Engineering, Guinea
Cottrino, Sandrine; France
Cress, Cory D.; United States Naval Research Laboratory, United States
Dancette, Sylvain; France
Degezelle, Dieter; Hamamatsu Photonics, Belgium
Eftekhari, Ali; Jimma University, Ethiopia
Espinosa, M. Renan; SKM Jacobs, Chile
Fauth, Melissa J.; Fritsch Milling and Sizing USA, United States
Feng, Zongqiang; China
Feng, Yuqing; CSIRO, Australia
Fischer, Torben; Helmholtz- Zentrum Geesthacht, Germany
Gleason, Barbara; United States
Gokhale, Atul; 212 Partners LLC, United States
Guraya, Teresa; University of the Basque Country, Spain
Harker, Nick; European Synchrotron Radiation Facility, France
Higashida, Kenji; Kyushu University, Japan
Holzner, Christian; Carl Zeiss X-Ray Microscopy Inc, United States
Howell, Jane; United States
Jacobs, Patric J.S.; Ghent University, Belgium
James, Agboita; Al-Ashmi Group, Qatar
Jimenez Pique, Emilio; University Politecnica Catalunya, Spain
Jones, Helen G.; National Physical Laboratory, Great Britain
Jorgensen, Peter S.; Technical University of Denmark, Denmark
King, Andrew; Synchrotron SOLEIL, France
Kobayashi, Masakazu; Toyohashi University of Technology, Japan
Konijnenberg, Peter J.; Max- Planck-Institute for Iron Research, Germany
Krill, Carl E.; Ulm University, Germany
Ku, Ching-Shun; National Synchrotron Radiation Research Center, Taiwan
Lee, David; Gordon College, United States
Lhuissier, Pierre; Grenoble University Alpes, France
Lienert, Ulrich; Deutsches Elektronen-Synchrotron, Germany

Limodin, Nathalie; Lille Laboratory of Mechanics, France

Lottermoser, Lars; HelmholtzZentrum Geesthacht, Germany

Ludwig, Wolfgang; CNR/ESRF, France

Luetje, Martin; University of Kassel, Germany

Lyckegaard, Allan; Xnovo Technology, Denmark

Maire, Eric; University De Lyon, France

Martin, Christophe, L.; University of Grenoble Alpes, France

Meinel, Dietmar; BAM, Germany

Mingard, Kenneth, P.; National Physical Laboratory, Great Britain

Mioduszewski, Melany; United States

Moonen, Peter; University of Pau and Pays de L'Adour, France

Mueter, Dirk; University of Copenhagen, Denmark

Patala, Srikanth; North Carolina State University, United States

Pecanac, Goran; Julich Research Centre, Germany

Perez-Willard, Fabian; Germany

Pike, Lee M.; Haynes International Inc, United States

Reid, Andrew; National Institute of Standards and Technology, United States

Reischig, Peter; Xnovo Technology, Denmark

Richards, Von L.; Missouri University of Science and Technology, United States

Rosa, Angelika D.; University De Lille 1, France
Roux, Stephane; National Center for Scientific Research, France

Salvo, Luc; University Grenoble, France

Scudder, Kevin; Gatan Inc, Great Britain

Sello, Maitse, P.; Hilliside Aluminium, South Africa

Serris, Eric; École Des Mines De Saint-Etienne, France

Soicher, Matthew A.; BEC Consulting, United States

Sorensen, Henning O:; University of Copenhagen, Denmark

Tafen, De Nyago; National Energy Technology Laboratory - URS, United States

Takebayashi, Seiki; Nippon Steel and Sumitomo Metal Corporation, Japan

Teeling, David R.; Rolls-Royce, Scotland

Timokhina, Ilana; Deakin University, Australia

Toda, Hiroyuki; Kyushu University, Japan

Wirjadi, Oliver; Fraunhofer Institute for Industrial Mathematics-ITWM, Germany

Wolfe, Douglas E.; Pennsylvania State University, United States

Wright, Jon; European Synchrotron Radiation Facility, France

Yamanaka, Akinori; Tokyo University of Agriculture \& Technology, Japan

Youssef, Souhail; IFP Energies Novelles, France

Ziehmer, Markus; Germany 